\title{
Persistence of Vascular Calcification after Reversal of Uremia
}

\author{
Koba A. Lomashvili, ${ }^{*}$ Kelly E. Manning, ${ }^{*}$ M. Neale Weitzmann, ${ }^{\dagger \ddagger}$ Valentin Nelea, ${ }^{\S}$ Marc D. McKee, ${ }^{\S}$ and W. Charles $0^{\prime}$ Neill*
}

From the Renal Division* and Division of Endocrinology and Metabolism, ${ }^{\dagger}$ Department of Medicine, Emory University School of Medicine, Atlanta, Georgia; the Atlanta Department of Veterans Affairs Medical Center ${ }^{\ddagger}$ Decatur, Georgia; and the Faculty of Dentistry ${ }^{\S}$ and Department of Anatomy and Cell Biology, McGill University, Montréal, Québec, Canada

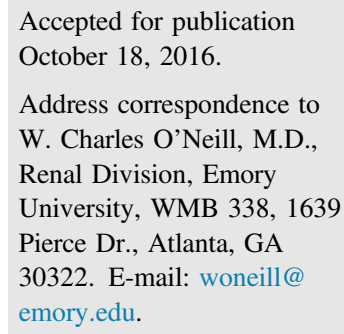

\begin{abstract}
The extent to which vascular calcification is reversible and the possible mechanisms are unclear. To address this, calcified aortas from uremic mice were transplanted orthotopically into normal mice, and the calcium content, histology, and minerals of the allografts were compared with the nontransplanted donor aorta. Calcium content decreased immediately after transplantation but remained constant thereafter, with $68 \% \pm 12 \%$ remaining after 34 weeks. X-ray diffraction showed the presence of apatite in both donor aortas and allografts. Osteoclasts were absent in the allografts and there was no expression of the macrophage marker CD11b, the osteoclast marker tartrate-resistant acid phosphatase, or carbonic anhydrase II. The initial loss of calcium was less in heavily calcified aortas and was associated with an increase in the $\mathrm{Ca} / \mathrm{P}$ ratio from 1.49 to 1.63 , consistent with a loss of nonapatitic calcium. The results indicate that vascular calcification persists after reversal of uremia, because of a lack of active resorption of apatite. This failure to resorb established calcifications may contribute to the severity of vascular calcification and suggests that therapy should be aimed at prevention. (Am J Pathol 2017, 187: 332-338; http://dx.doi.org/10.1016/j.ajpath.2016.10.006)
\end{abstract}

Calcification of the medial layer of arteries is common in patients with chronic kidney disease, diabetes, or advanced age, ${ }^{1-5}$ and is thought to be detrimental because of arterial stiffening. ${ }^{6}$ Although therapies exist to slow or prevent calcification in chronic kidney disease, the extent to which this process is reversible remains unclear. Although reversibility of uremic vascular calcification has been reported in humans, ${ }^{7}$ this has not been observed in any large interventional studies aimed at correcting disordered mineral metabolism in patients with chronic kidney disease or endstage renal disease. Studies in patients before and after renal transplantation have shown regression ${ }^{8}$ or no change ${ }^{9}$ in coronary artery calcification. However, this calcification is largely atherosclerotic ${ }^{10}$ and can progress after transplantation as a result of other metabolic factors. ${ }^{11}$ Studies in uremic animals have been limited to an atherosclerotic model in mice in which sevelamer appeared to reverse some calcification. ${ }^{12}$ Reversibility of medial calcification has been shown in nonuremic animal models ${ }^{13-15}$ and in patients with generalized arterial calcification of infancy. ${ }^{16}$ However, we did not observe significant reversal of calcification after aortic transplantation in an animal model of this disorder. $^{17}$

Vascular calcifications are composed primarily of apatitic mineral with varying amounts of whitlockite, ${ }^{18,19}$ both of which are highly insoluble under physiological conditions ${ }^{20}$ and thus are not expected to disappear spontaneously. Apatite appears not to form spontaneously from calcium and phosphate ions, whereas initially brushite $\left(\mathrm{CaHPO}_{4} 2 \mathrm{H}_{2} \mathrm{O}\right)$ and/or other intermediates (including amorphous calcium phosphate) that are more soluble may be present in variable amounts in calcified vessels. ${ }^{21,22}$ Thus, some spontaneous reversal of vascular calcification in the early, pre-apatitic stage is possible. However, apatite is quite soluble at an acidic $\mathrm{pH}$, and resorption of bone, where apatite is abundant, requires acid-producing osteoclasts. Thus, it is likely that a similar process involving acidic conditions would be required to remove established vascular calcifications. Osteoclasts are occasionally observed in calcified arteries

Supported by NIH grant K08 DK079176 (K.A.L.).

Disclosures: None declared. 


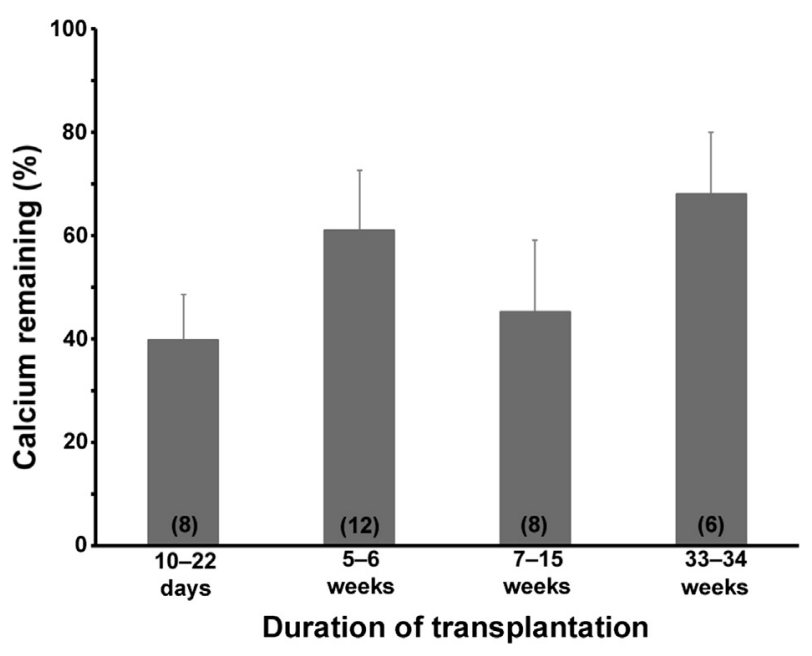

Figure 1 Excess calcium content of aortic allografts expressed as a percentage of the calcium content of the donor aorta. Error bars denote standard errors. Numbers within parentheses indicate the number of allografts. Each group was significantly less than 100\% (by paired $t$-test), but there was no difference between the groups $(P=0.30$ by analysis of variance).

but they are rare and osteoclast-mediated resorption has not been shown. ${ }^{23}$ Alternatively, resorption potentially could be mediated by acid produced from smooth muscle cells, which is consistent with the up-regulation of carbonic anhydrase II in warfarin-mediated vascular calcification ${ }^{15}$ and the vascular calcification observed in mice lacking this enzyme. ${ }^{24}$

To determine the extent to which the medial arterial calcification observed in uremia is reversible, calcified aortas from uremic mice fed a high-phosphate diet were transplanted into normal mice. Calcium content, mineral analysis, and histology were examined in allografts over time and compared with segments of the donor aortas that were not transplanted.

\section{Materials and Methods}

\section{Uremic Vascular Calcification}

Uremia was induced in C57BL6 mice by feeding adenine as previously described. ${ }^{25}$ Powdered adenine was mixed with standard rodent chow at $0.45 \%(\mathrm{wt} / \mathrm{wt})$. Vascular calcification was induced by adding sodium phosphate (neutral mixture of $\mathrm{Na}_{2} \mathrm{HPO}_{4}$ and $\mathrm{NaH}_{2} \mathrm{PO}_{4}$ ) to the diet at a final content of $2 \%$ and by s.c. injections of calcitriol $(1 \mu \mathrm{g} / \mathrm{kg})$ 3 times per week.

\section{Transplantation}

Transplantation was performed as previously described. ${ }^{17}$ Segments (4 to $5 \mathrm{~mm}$ ) of infrarenal aortas were dissected carefully from the uremic mice and the remaining aorta was saved for histology and measurement of calcium content. A corresponding segment of aorta was removed from a healthy littermate and replaced with the calcified aorta via end-toend anastomoses with 11-0 monofilament sutures. The allografts and anastomotic sites were pretreated with heparin $(200 \mathrm{U} / \mathrm{mL})$ to prevent thrombosis. Sex was not matched except that male aortas were not transplanted into female mice to avoid rejection based on Y-chromosome-specific epitopes. Animals were sacrificed and aortas were removed at the end of the study. Tissue within $0.5 \mathrm{~mm}$ of each side of the suture lines was excluded from analyses. All animal procedures were approved by the Institutional Animal Care and Use Committee of Emory University.

\section{Staining Procedures}

Freshly isolated aortas were stained with a freshly prepared solution of one volume of ethanol saturated with alizarin red $\mathrm{S}$ and 24 volumes of $0.5 \% \mathrm{KOH}$ for 12 hours. Staining with hematoxylin and eosin and von Kossa were performed on

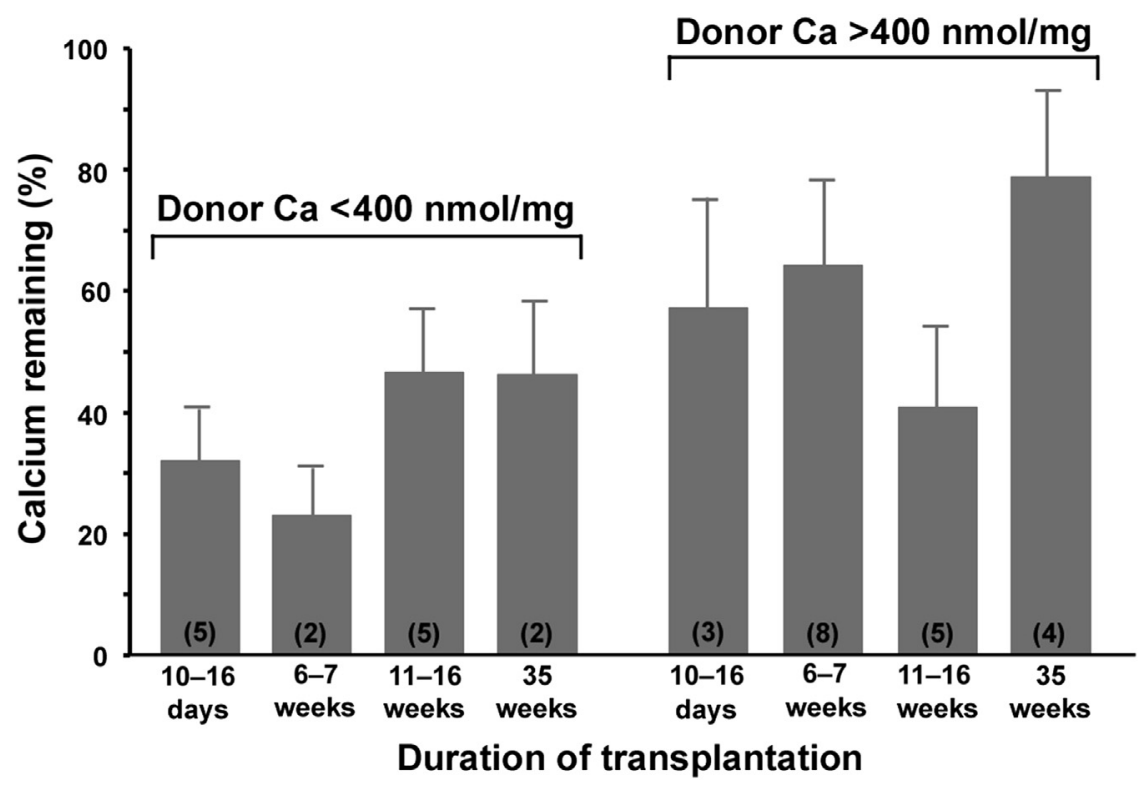

Figure 2 Excess calcium content of aortic allografts from mildly and heavily calcified donor aortas expressed as a percentage of the calcium content of the donor aorta. Error bars denote standard errors. Numbers within parentheses indicate the number of allografts. There were no differences between groups by analysis of variance. 
5 - $\mu \mathrm{m}-$ thick sections of formalin-fixed aortas mounted in OCT medium according to standard procedures. Staining for tartrate-resistant acid phosphatase was performed with a leukocyte acid phosphatase kit (387A-1KT; Sigma-Aldrich, St. Louis, MO). Immunohistochemistry was performed using polyclonal rabbit antibody against carbonic anhydrase II and a rabbit monoclonal antibody against CD11b (both from Abcam, Cambridge, MA).

\section{Measurement of Aortic Calcium and Phosphate}

Calcium content was measured as previously described, ${ }^{17}$ with some changes. After staining with alizarin red S, the aortas were destained with $0.05 \% \mathrm{KOH}$, rinsed in physiological saline without calcium, and extracted in $50 \mu \mathrm{L}$ of $1 \mathrm{~mol} / \mathrm{L} \mathrm{HCl}$ overnight. Calcium content in the extracts then was measured by the cresophthalein method. Preliminary testing showed that the prior alizarin red staining and destaining did not remove calcium or interfere with the assay. Phosphate was measured colorimetrically by the molybdate method. ${ }^{26}$

\section{X-Ray Diffraction}

Measurements were performed with a D8 DISCOVER diffractometer (Bruker-AXS, Inc., Billerica, MA), equipped with a copper X-ray tube (wavelength, $1.54056 \AA$ ). Multiple paraffin sections from individual aortas/allografts were detached with a fine scalpel blade from glass slides and pooled and homogenized by grinding between two glass slides.

\section{Statistical Analysis}

Differences in calcium content were analyzed by $t$-test, with $P<0.05$ considered significant.

\section{Results}

Previous studies have shown that mice were more sensitive than rats to adenine with a dietary content of $0.45 \%$ sufficient to cause renal failure ${ }^{25}$ compared with $0.75 \%$ in rats. However, mice are more resistant to vascular calcification, necessitating the use of a higher dietary phosphate level (2\% versus $0.73 \%$ to $1.06 \%)$ and larger doses of calcitriol (1000 $\mathrm{ng} / \mathrm{kg}$ versus 40 to $100 \mathrm{ng} / \mathrm{kg}$ ) than in rats. Adenine was started at age $117 \pm 7$ days and continued for $127 \pm 8$ days. Plasma urea, calcium, and phosphorus values were $21.6 \pm 1.3 \mathrm{mmol} / \mathrm{L}, 1.65 \pm 0.12 \mathrm{mmol} / \mathrm{L}$, and $4.25 \pm 0.38$ $\mathrm{mmol} / \mathrm{L}$, respectively, in uremic mice, and $2.45 \pm 0.17$ $\mathrm{mmol} / \mathrm{L}, 1.83 \pm 0.07 \mathrm{mmol} / \mathrm{L}$, and $2.52 \pm 0.09 \mathrm{mmol} / \mathrm{L}$ in control mice. The calcium content in the aortas of uremic mice was $1155 \pm 270 \mathrm{nmol} / \mathrm{mg}$, but varied considerably from 22 to $4262 \mathrm{nmol} / \mathrm{mg}$. Calcium content in normal aorta, measured in recipient aortas, was $5.4 \pm 0.4 \mathrm{nmol} / \mathrm{mg}$. This value was subtracted from that in the calcified aortas to determine the amount of excess calcium.
Segments of calcified abdominal aorta approximately 4 to $5 \mathrm{~mm}$ in length were removed from uremic mice and placed orthotopically into the abdominal aorta of nonuremic littermates. A total of 36 successful transplantations were performed in recipients aged $243 \pm 11$ days, of which 13 were female into female, 8 were female into male, and 15 were male into male. Male to female transplantation was not performed because of concern regarding possible rejection owing to genes present on the $\mathrm{Y}$ chromosome. There were three perioperative deaths. The allografts were harvested at 2 to 3,5 to 6,11 to 15 , or 33 to 34 weeks after transplantation and were compared with untransplanted aorta from the respective donors. All but two allografts had an excess calcium content that was the same or lower than in the donor aorta. Two allografts (11 and 13 weeks after transplant) showed very large proportional increases in calcium content compared with the donor aorta $(292 \%$ and $573 \%$ of donor content) despite small absolute increases in calcium content ( 22 and $143 \mathrm{nmol} / \mathrm{mg}$ ). This was owing to the minimal calcification of the donor aortas (12 and 30 $\mathrm{nmol} / \mathrm{mg}$ ); to avoid substantial skewing of the data these
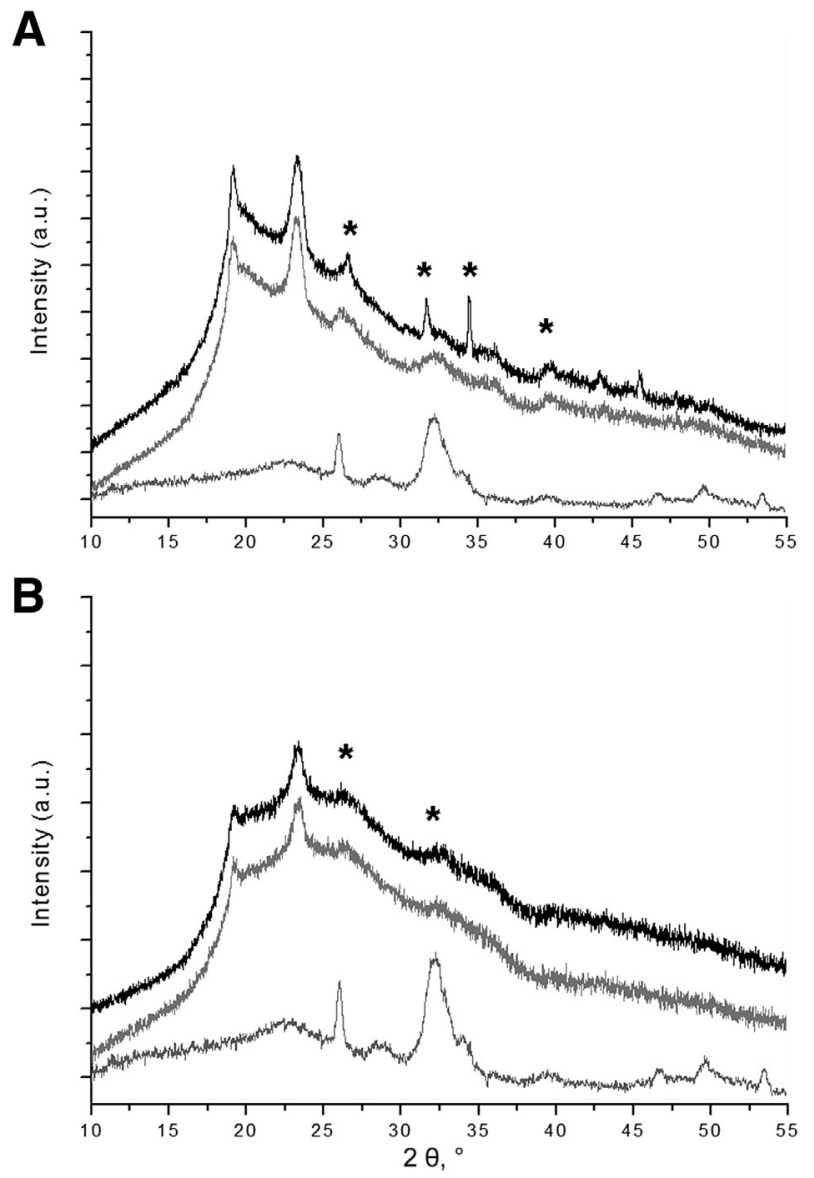

Figure $3 \quad X$-ray diffraction of calcified aortas. A: Uremic calcified aortas (top two spectra). B: Allografts at 2 weeks (top spectra) and at 8 months (middle spectra). Bottom spectra are X-ray diffraction patterns of mouse bone apatite. Asterisks indicate hydroxyapatite peaks. The two unlabeled peaks to the left of the asterisks derive from the OCT embedding medium. a.u., arbitrary unit. 
two allografts were omitted from the analyses. We previously have shown that there is no change in calcium content when normal aortas are transplanted into normal mice. ${ }^{17}$

For the remaining 34 allografts, the excess calcium was $52 \% \pm 5 \%$ of that in the paired donor aortas (range, $4 \%$ to $109 \% ; P<0.0001)$ and, as shown in Figure 1, the decrease occurred entirely within the first 2 weeks and did not progress with longer transplant durations. Calcium contents for each transplantation are shown in Supplemental Figure S1. There was no decrease in the calcium content when calcified aortas were placed in tissue culture medium (Dulbecco's modified Eagle's medium) in a $\mathrm{CO}_{2}$ incubator for 24 hours (data not shown), suggesting that there is not an immediate dissolution of calcium after harvesting of the uremic aortas. Although the calcium content of the allografts appeared to increase over time, this was not statistically significant and likely represents variability caused by heterogeneity in calcification. There was no significant correlation between the percentage of remaining calcium and the duration of uremia $(r=0.22)$, age at transplantation $(r=0.26)$, the transplant duration $(r=0.26)$, or the donor aortic calcium content $(r=0.05)$. The percentage of remaining calcium was greater in allografts from heavily calcified $(>400 \mathrm{nmol} / \mathrm{mg} ; n=20)$ versus less calcified $(<400 \mathrm{nmol} / \mathrm{mg} ; n=14)$ donor aortas $(60.4 \pm 7.5$ versus $38.2 \pm 5.8 ; P=0.037)$, but the temporal pattern was unchanged (Figure 2). Calcium contents $>400 \mathrm{nmol} / \mathrm{mg}$ result in dense, concentric calcification.

The ratio of calcium to phosphate also was compared in allografts and nontransplanted donor aortas. The ratio in allografts was $1.63 \pm 0.04$, close to that of pure hydroxyapatite (1.67). The ratio in the donor aortas was significantly lower $(1.49 \pm 0.05 ; P<0.05)$, consistent with a greater proportion of nonapatitic precursors or amorphous compounds. X-ray diffraction showed the presence of apatite in calcified uremic aortas and allografts (Figure 3). This apatitic phase had a poor crystalline structure typical of the biological apatite observed in bone, as shown by the broader diffraction peaks. However, peak broadening was enhanced, and their intensities were much lower in allografts than that observed in uremic aortas, suggesting a reduction in the apatitic mineral phase in the transplanted aortas.

Figure 4 shows the macroscopic and microscopic appearance of the aortic calcifications as shown by alizarin red staining of the luminal surface or by von Kossa staining of formalin-fixed sections. The calcification was exclusively medial, as observed with the adenine model in rats. There was occasional fracturing of the calcified internal elastic lamina and sloughing of the intima during the preparation for histology. Consistent with humans and in other animal models, the calcification was heterogeneous, but there was no obvious difference in the pattern between allografts and donor aortas, or with the duration of transplantation. Staining of allografts with hematoxylin and eosin did not show any inflammatory cell infiltrates or multinucleated cells (Figure 5). The absence of inflammatory cells and osteoclasts was confirmed by staining for CD11b, a marker of murine macrophages (Figure 6, A and B), and staining for tartrate-resistant acid phosphatase (Figure 6, C and D). There was also no cellular staining for carbonic anhydrase II
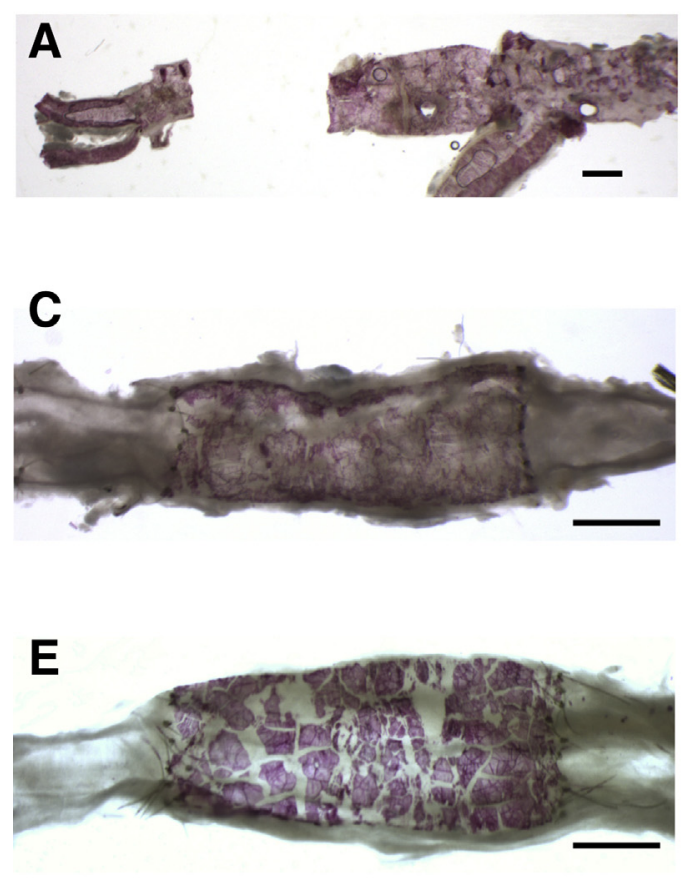

\section{B}
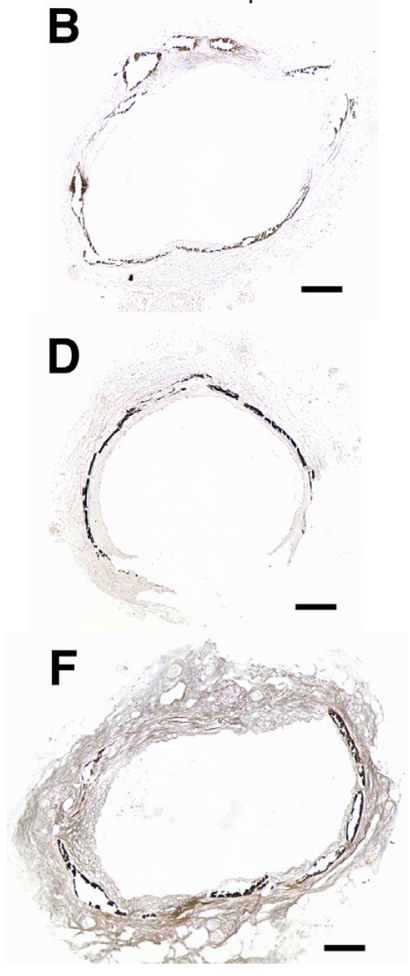

Figure 4 Calcification of donor aortas and allografts. A, C, and E: Alizarin red stain. B, D, and F: von Kossa stain. A: Donor aorta. C: Allograft from aorta shown in A, 10 weeks after transplantation. E: Heavily calcified allograft 34 weeks after transplantation. B: Donor aorta. D: Allograft from aorta shown in B, 6 weeks after transplantation. F: Allograft 35 weeks after transplantation. Some fracturing of the calcifications occurred during preparation of the vessels. Scale bars: $1 \mathrm{~mm}(\mathbf{A}, \mathbf{C}$, and $\mathbf{E}) ; 100 \mu \mathrm{m}$ (B, D, and $\mathbf{F})$. 

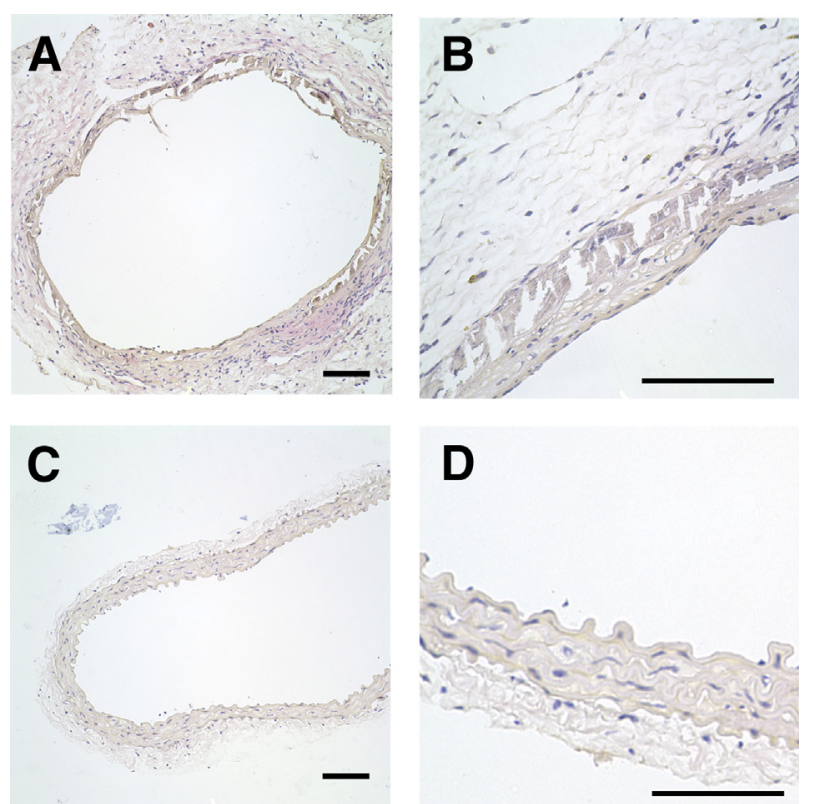

Figure 5 Histology of calcified aortic allografts (hematoxylin and eosin staining). A: Seventy-five days after transplant (low magnification). B: Thirty-nine days after transplant (high magnification). C: Noncalcified segment from same allograft as in B. D: Enlarged view of C. Scale bars = $100 \mu \mathrm{m}$.

(Figure 6, E and F). In each case, at least five separate allografts (four sections per allograft) were examined.

\section{Discussion}

Aortic transplantation provides a unique opportunity to examine the reversibility of vascular calcification because a normal internal milieu is restored immediately. Immunologic changes related to transplantation are minimized by using littermates, and this was confirmed by the absence of cellular infiltrates and macrophages. This model has been used previously to distinguish between local and systemic factors in vascular calcification, also without any signs of cell-mediated rejection. ${ }^{17,25}$ Calcification of the aortas renders the transplantation more challenging; however, despite that, the surgical survival rate was greater than $90 \%$.

The major finding in this study was the stable persistence of vascular calcifications after transplantation for up to 34 weeks. Presumably, the calcification process was halted by transplantation into normal mice, but it is possible that the calcifications could serve as nucleation sites for further calcification under normal conditions. Injury associated with transplantation does not contribute to the persistence of the calcifications because we previously have shown no calcification in aortic allografts from normal mice. ${ }^{17,25}$

No evidence was found for active resorption of the calcifications. Apatite is highly insoluble under physiological conditions and requires an acid environment for dissolution that, in bone, is created by osteoclasts. Presumably, this could also be accomplished through phagocytosis by macrophages, with subsequent dissolution in acidic lysosomes, but this would be limited to small isolated crystals or small crystal aggregates. However, there was no histologic evidence of cellular infiltrates, multinucleated cells, macrophages, or osteoclasts. Although osteoclasts occasionally are observed in calcified human arteries ${ }^{23}$ and heart valves ${ }^{27}$ their presence is very rare, and evidence that they actively resorb calcifications is lacking.

Another potential mechanism for resorption of calcification is acid generation by adjacent smooth muscle cells, which would require carbonic anhydrase to generate carbonic acid. Up-regulation of carbonic anhydrase II has been shown in smooth muscle cells of calcified aortas from rats treated with warfarin,${ }^{15}$ and its absence in mice results in vascular calcification. ${ }^{24}$ However, there was no detectable expression of carbonic anhydrase II in calcified uremic aortas, either before or after transplantation. Whether the discrepancy with the warfarin-treated rats is because of the different model of vascular calcification is unclear.
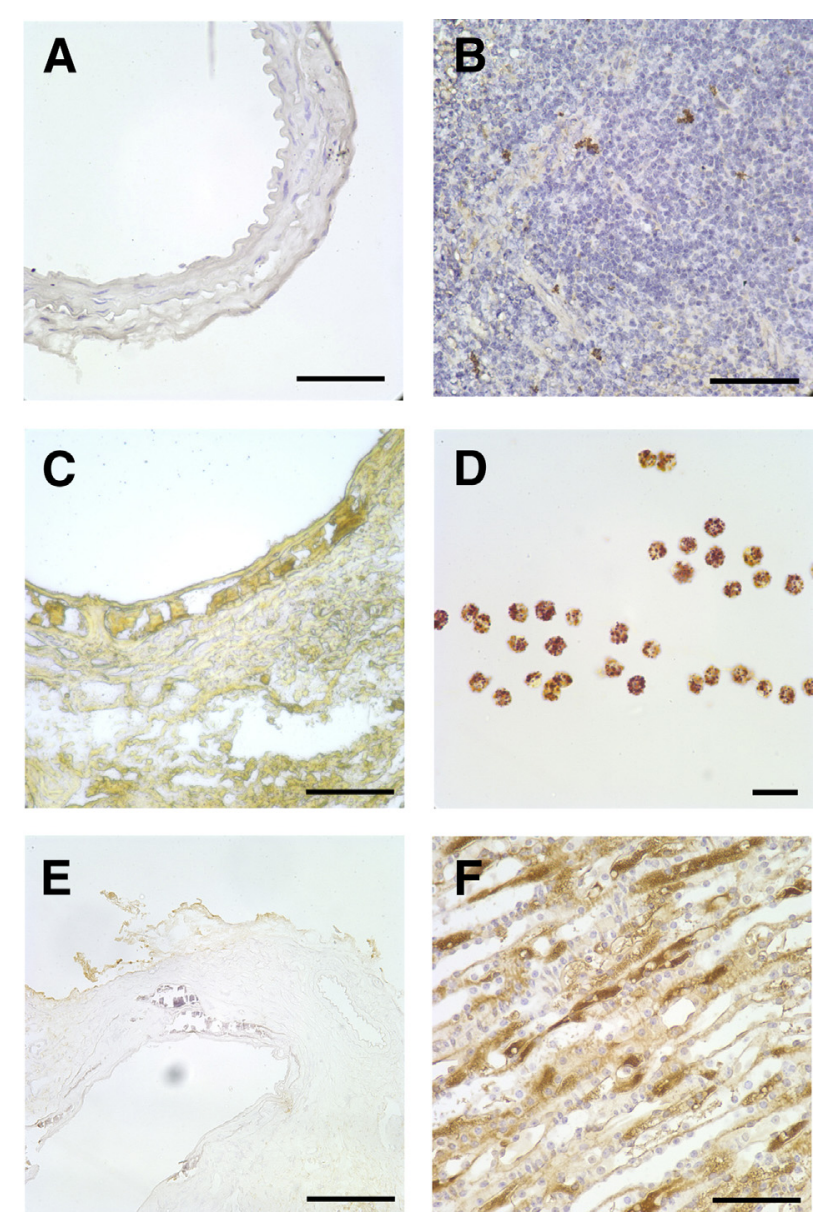

Figure 6 Histochemistry of aortic allografts. A: Immunohistochemistry for CD11b in a transplanted aorta. B: Positive staining for CD11b in mouse spleen. C: Histochemistry for tartrate-resistant acid phosphatase in a heavily calcified allograft. D: Positive staining for acid phosphatase in human neutrophils. E: Immunohistochemistry for carbonic anhydrase II in a calcified allograft. F: Positive staining for CA II in mouse kidney. Scale bars: $100 \mu \mathrm{m}$ (A, B, E, F); $50 \mu \mathrm{m}$ (C); $20 \mu \mathrm{m}$ (D). 
Despite the absence of active resorption, approximately half the calcium content disappeared from the calcified allografts within the first 2 weeks. Presumably, this occurred through spontaneous dissolution of more soluble precursors of apatite such as brushite $\left(\mathrm{CaHPO}_{4} \cdot 2 \mathrm{H}_{2} \mathrm{O}\right)$ and/or amorphous calcium phosphate, ${ }^{21,22}$ which is supported by the calcium/phosphorus ratios. In allografts, this ratio was 1.63 , which is close to that for stochiometric apatite (1.67). However, the ratio was lower in donor aortas, consistent with the presence of brushite $(\mathrm{Ca} / \mathrm{P}=1.0)$ and/or amorphous calcium phosphate. The fact that the proportional loss of calcium tended to be less in more heavily calcified allografts supports this interpretation because more heavily calcified aortas should have a proportionally higher apatite content. However, the X-ray diffraction data suggest some loss of apatite in allografts as well. If true, the mechanism is unclear and must be limited to a specific fraction of apatite because further removal of calcifications over time was not observed.

Previous animal studies on the reversibility of medial arterial calcification have been limited to models in which the underlying cause could be removed. ${ }^{13-15}$ In a model of acute calcitriol toxicity in rats, there was progressive resolution of the calcification during the 9 weeks after calcitriol was stopped. ${ }^{14}$ However, $28 \%$ of the calcium content still remained after 9 weeks, and longer time points were not examined. It is unlikely that significant quantities of apatite would form during just 8 days of calcitriol treatment. In a model of warfarin-induced vascular calcification over 6 weeks, calcification was not reduced and actually continued to increase after warfarin was stopped. ${ }^{13}$ Reversal was observed when high doses of vitamin $\mathrm{K}$ were added, with $60 \%$ of the calcium remaining after 6 weeks, similar to the proportion of residual calcium in transplanted uremic aortas. Similarly, 53\% of warfarin-induced vascular calcification in another study remained 18 weeks after stopping the warfarin. ${ }^{15}$

Reversal of vascular calcification has been shown most clearly in generalized arterial calcification of infancy. This disorder is due to a deficiency of ectonucleotide pyrophosphatase pyrophosphorylase, an enzyme that produces pyrophosphate, a key inhibitor of ectopic calcification. ${ }^{28,29}$ Complete radiologic resolution of calcifications has been reported in children even without specific therapy. ${ }^{16,30-34}$ However, we observed no regression of aortic calcification when aortas from a mouse model of this disease were transplanted into normal mice. ${ }^{17}$ The mechanism of reversal has not been explored and whether this is related to continued growth of the arteries during development or whether calcification remains histologically is unclear.

Although reversal of uremia has not been examined, evidence for some reversal of atherosclerotic calcification has been shown in uremic mice after treatment with sevelamer. ${ }^{12}$ However, it is not known whether this was because of reversal of the atherosclerosis or the calcification. There was no reversal of aortic calcification when uremic rats were switched from a high-phosphate diet to a low-phosphate diet for 28 days, although there may have been some reversal in rats treated with a calcimimetic. ${ }^{35}$ In contrast, reversal of aortic valve calcification in uremic rats was shown after removal of adenine and supplemental phosphate from the diet. $^{36}$ The mechanism of the calcium resorption was not investigated.

Whether uremic vascular calcification is reversible in humans remains unclear. A 39\% decrease in coronary artery calcification, similar to that observed in mouse aortic allografts, was found 6 months after renal transplantation in 31 patients. ${ }^{8}$ However, no change was noted after renal transplantation in another study. ${ }^{9}$ Although renal failure was eliminated, this experimental approach was complicated by the metabolic derangements in transplant patients that can cause progression of atherosclerosis and the accompanying calcification. ${ }^{11}$ Treatments to correct altered mineral metabolism in patients with renal failure can slow progression of vascular calcification, but reversal has not been shown. Treatment with etidronate appeared to reduce coronary artery calcification in some, but not all, patients with endstage renal disease. ${ }^{37}$

In summary, there was no evidence of active resorption of uremic vascular calcification when calcified aortas were transplanted into normal animals. Although there was rapid disappearance of a portion of the excess calcium in uremic aortas, the majority of the excess calcium, likely representing poorly crystalline apatite, remains over time, with no evidence of removal. The absence of active resorption may contribute to the severity of vascular calcification and supports a preventative approach to vascular calcification.

\section{Supplemental Data}

Supplemental material for this article can be found at http://dx.doi.org/10.1016/j.ajpath.2016.10.006.

\section{References}

1. Abou-Hassan N, D'Orsi ET, D'Orsi CJ, O'Neill WC: The risk for medial arterial calcification in CKD. Clin J Am Soc Nephrol 2012, 7: 275-279

2. Lehto S, Niskanen L, Suhonen M, Ronnemaa T, Laakso M: Medial artery calcification. A neglected harbinger of cardiovascular complications in non-insulin-dependent diabetes mellitus. Arterioscler Thromb Vasc Biol 1996, 16:978-983

3. Iribarren C, Go AS, Tolstykh I, Sidney S, Johnston SC, Spring DB: Breast vascular calcification and risk of coronary heart disease, stroke, and heart failure. J Womens Health 2004, 13:381-389

4. Chowdhury UK, Airan B, Mishra PK, Kothari SS, Subramaniam GK, Ray R, Singh R, Venugopal P: Histopathology and morphometry of radial artery conduits: basic study and clinical application. Ann Thorac Surg 2004, 78:1614-1622

5. Everhart JE, Pettitt DJ, Knowler WC, Rose FA, Bennett PH: Medial arterial calcification and its association with mortality and complications of diabetes. Diabetologia 1988, 31:16-23 
6. Blacher J, Guerin AP, Pannier B, Marchais SJ, London GM: Arterial calcifications, arterial stiffness, and cardiovascular risk in end-stage renal disease. Hypertension 2001, 38:938-942

7. Verberckmoes R, Bouillon R, Krempien B: Disappearance of vascular calcifications during treatment of renal osteodystrophy. Ann Intern Med 1975, 82:529-533

8. Abedi SA, Tarzamni MK, Nakhjavani MR, Bohlooli A: Effect of renal transplantation on coronary artery calcification in hemodialysis patients. Transplant Proc 2009, 41:2829-2831

9. Moe SM, O’Neill KD, Resterova M, Fineberg N, Persohn S, Meyer CA: Natural history of vascular calcification in dialysis and transplant patients. Nephrol Dial Transplant 2004, 19:2387-2393

10. Nakamura S, Ishibashi-Ueda H, Niizuma S, Yoshihara F, Horio T, Kawano Y: Coronary calcification in patients with chronic kidney disease and coronary artery disease. Clin J Am Soc Nephrol 2009, 4: 1892-1990

11. Marechal C, Coche E, Goffin E, Dragean A, Schlieper G, Nguyen P, Floege J, Kanaan N, Devuyst O, Jadoul M: Progression of coronary artery calcification and thoracic aorta calcification in kidney transplant recipients. Am J Kidney Dis 2012, 59:258-269

12. Mathew S, Lund RJ, Strebeck F, Tustison KS, Geurs T, Hruska KA: Reversal of the adynamic bone disorder and decreased vascular calcification in chronic kidney disease by sevelamer carbonate therapy. J Am Soc Nephrol 2007, 18:122-130

13. Schurgers LJ, Spronk HMH, Soute BAM, Schiffers PM, DeMey JGR, Vermeer C: Regression of warfarin-induced medial elastocalcinosis by high intake of vitamin $\mathrm{K}$ in rats. Blood 2007, 109:2823-2831

14. Bas A, Lopez I, Perez J, Rodriguez M, Aguilera-Tejero E: Reversibility of calcitriol-induced medial artery calcification in rats with intact renal function. J Bone Miner Res 2006, 21:484-490

15. Essalihi R, Dao HH, Gilbert LA, Bouvet C, Semerjian Y, McKee MD, Moreau P: Regression of medial elastocalcinosis in rat aorta. A new vascular function for carbonic anhydrase. Circulation 2005, 112:1628-1635

16. Otero JE, Gottesman GS, McAlister WH, Mumm S, Madson KL, Kiffer-Moreira T, Sheen C, Millan JL, Ericson KL, Whyte MP: Severe skeletal toxicity from protracted etidronate therapy for generalized arterial calcification of infancy. J Bone Miner Res 2013, 28:419-430

17. Lomashvili KA, Narisawa S, Millan JL, O’Neill WC: Vascular calcification is dependent on plasma levels of pyrophosphate. Kidney Int 2014, 85:1351-1356

18. LeGeros RZ, Contiguglia SR, Alfrey AC: Pathological calcifications associated with uremia. Calcif Tissue Res 1973, 13:173-185

19. Verberckmoes SC, Persy V, Behets GJ, Neven E, Hufkens A, ZebgerGong H, Muller D, Haffner D, Querfeld U, Bohic S, De Broe ME, D'Haese PC: Uremia-related vascular calcification. More than apatite deposition. Kidney Int 2007, 71:298-303

20. O'Neill WC: Vascular calcification: not so crystal clear. Kidney Int 2007, 71:282-283

21. Neuman WF, Neuman MW: The Chemical Dynamics of Bone Mineral. Chicago, IL: University of Chicago Press, 1958

22. Johnsson MS, Nancollas GH: The role of brushite and octacalcium phosphate in apatite formation. Crit Rev Oral Biol Med 1992, 3:61-82
23. Han KH, Hennigar RA, O'Neill WC: The association of bone and osteoclasts with vascular calcification. Vasc Med 2015, 20:527-533

24. Spicer SS, Lewis SE, Tashian RE, Schulte BA: Mice carrying a CAR-2 null allele lack carbonic anhydrase 11 immunohistochemically and show vascular calcification. Am J Pathol 1989, 134:947-954

25. Lomashvili KA, Wang X, O'Neill WC: Role of local versus systemic vitamin D receptors in vascular calcification. Arterioscler Thromb Vasc Biol 2014, 34:146-151

26. Cogan EB, Birrell GB, Griffith OH: A robotics-based automated assay for inorganic and organic phosphates. Anal Biochem 1999, 271:29-35

27. Mohler ER, Gannon F, Reynolds C, Zimmerman R, Keane M, Kaplan FS: Bone formation and inflammation in cardiac valves. Circulation 2001, 103:1522-1528

28. Rutsch F, Vaingankar S, Johnson K, Goldfine I, Maddux B, Schauerte P, Kalhoff H, Sano K, Boisvert WA, Superti-Furga A, Terkeltaub RA: PC-1 nucleotide triphosphate pyrophosphohydrolase deficiency in idiopathic infantile arterial calcification. Am J Pathol 2001, 158:543-554

29. Lomashvili KA, Cobbs S, Hennigar RA, Hardcastle KI, O’Neill WC: Phosphate-induced vascular calcification: role of pyrophosphate and osteopontin. J Am Soc Nephrol 2004, 15:1392-1401

30. Sholler GF, Yu JS, Bale PM, Hawker RE, Celermajer JM, Kozlowski K: Generalized arterial calcification of infancy: three case reports, including spontaneous regression with long-term survival. J Pediatr 1984, 105:257-260

31. Marrott PK, Newcombe KD, Becroft DM, Friedlander DH: Idiopathic infantile arterial calcification with survival to adult life. Pediatr Cardiol 1984, 5:119-122

32. Ciana G, Trappan A, Bembi B, Benettoni A, Maso G, Zennaro F, Ruf N, Schnabel D, Rutsch F: Generalized arterial calcification of infancy: two siblings with prolonged survival. Eur J Pediatr 2006, 165: $258-263$

33. Miyai K, Ariyasu D, Numakura C, Yoneda K, Nakazato H, Hasegawa Y: Hypophosphatemic rickets developed after treatment with etidronate disodium in patient with generalized arterial calcification in infancy. Bone Rep 2015, 3:57-60

34. Ferreira CR, Ziegler SG, Gupta A, Groden C, Hsu KS, Gahl WA: Treatment of hypophosphatemic rickets in generalized arterial calcification of infancy (GACI) without worsening of vascular calcification. Am J Med Genet A 2016, 170A:1308-1311

35. Lopez I, Mendoza FJ, Guerrero F, Almaden Y, Henley C, AguileraTejero E, Rodriguez M: The calcimimetic AMG 641 accelerates regression of extraosseous calcification in uremic rats. Am J Physiol Renal Physiol 2009, 296:F1376-F1385

36. Shuvy M, Abedat S, Beeri R, Danenberg HD, Planer D, Ben-Dov IZ, Meir K, Sosna J, Lotan C: Uraemic hyperparathyroidism causes a reversible inflammatory process of aortic valve calcification in rats. Cardiovasc Res 2008, 79:492-499

37. Nitta K, Akiba T, Suzuki K, Uchida K, Watanabe RY, Majima K, Aoki T, Nihei H: Effects of cyclic intermittent etidronate therapy on coronary artery calcification in patients receiving long-term hemodialysis. Am J Kidney Dis 2004, 44:680-688 